\title{
Evaluation of Materials in a Biomechanical System for Uses in Industrial Lifting Activities
}

\author{
Roberto L. Avitia, ${ }^{1}$ Gustavo L. Badilla, ${ }^{2}$ Rubén C. Martínez, ${ }^{3}$ Jose A. Cárdenas-Haro, ${ }^{4}$ \\ Marco A. Reyna, ${ }^{1}$ and Miguel E. Bravo-Zanoguera ${ }^{1}$ \\ ${ }^{1}$ Bioengineering and Environmental Health Department, Universidad Autónoma de Baja California, Mexicali, BC, Mexico \\ ${ }^{2}$ Tecnologico Nacional de Mexico, Mexicali, BC, Mexico \\ ${ }^{3}$ Instituto Tecnologico de Rehabilitacion, Mexicali, BC, Mexico \\ ${ }^{4}$ Computer Science Department, California State University, Bakersfield, CA, USA
}

Correspondence should be addressed to Roberto L. Avitia; ravitia@uabc.edu.mx

Received 23 September 2016; Revised 12 December 2016; Accepted 5 January 2017; Published 19 February 2017

Academic Editor: Sumin Kim

Copyright (C) 2017 Roberto L. Avitia et al. This is an open access article distributed under the Creative Commons Attribution License, which permits unrestricted use, distribution, and reproduction in any medium, provided the original work is properly cited.

\begin{abstract}
A biomechanical system is proposed for the emulation of the movement of human arm, leg, and spine movements, as an industry alternative to manage heavy operations in a manufacturing process. The Matlab ${ }^{\circledR}$ programming environment is used as a simulation tool for the analysis and validation of this proposed biomechanism. This machine would reduce the accidents due to human exposure to risky industry environments like the particular one at the host company that we are using as a model for our research. They claim that the accidents in this area alone arise to around thirty percent of the total, causing a decrease in the productivity of the company and other economic losses derived from the worker injuries and insurances.
\end{abstract}

\section{Introduction}

The materials science is an area of high interest in bioengineering and in the subfield of biomechanics. Any material required in the operations of a biomechanical system has to be evaluated carefully. There is a technological revolution in the medical sciences triggered by the biomechanics and bioengineering in general, used mainly in the design and manufacturing of systems that can replace the functions of human organs and muscles. The main motivation has been supplying the high demand generated by the people with disabilities around the world that depend on this kind of technological developments to live a better quality of life. The use of this kind of biomechanical systems is very uncommon in industry where the use of robots and automated equipment is the norm. The aim of this research is the design of a biomechanical system for its use in an industrial manufacturing process. The host company for this research and analysis is the "Industrial Metal, SA De CV" located in Mexicali, BC, Mexico. In this industry, the operation of interest for our study consists of an activity that require the lifting of heavy objects (over one hundred kilograms in weight) to a height up to two meters. This operation has been performed so far only by humans.

The most important factors in the fabrication of a biomechanical system are the design requirements and the materials that will be used for that. Some analysis is required prior to the selection of the materials to determine the mechanical resistance, stress, and strain levels as well as the presence of any possible corrosion phenomena. This system could improve the lives of people with some specific needs or at least give some comfort to many others. For example, when a limb is lost completely or partially by either birth defect, illness, or accident, this system could bring some relief for these people. Biomechanical engineering has been used largely to develop systems to support people with disabilities. This branch of bioengineering rarely has sparked interest in developing systems that could prevent injuries in the industrial plant areas where heavy duties and human endurance are demanded, lowering at the same 
time the consumption levels of energy. In order to fulfill the standards Newtonian mechanics is applied to materials science to obtain the adequate biomechanical systems that can be used in some specific industrial processes. The humanbody systems are too complex; thus numerical and graphical simulation methods are applied in all the biomechanical studies performed. In the design of the biomechanical systems the materials to be used can be evaluated according to the specific needs and applications of the work environment. In some ways, these systems are similar to the equipment and machinery used for lifting heavy objects. This work and research were carried out using an iterative approach of hypothesis and verification including multistage modeling, computer simulations, and experimental measurements. A model of the simulated biomechanical systems was previously developed based on the human kinetics to determine the mechanical, electrical, and electromechanical characteristics required for the controlling of the movements in the systems. The industrial kinesiology is of great importance in the design and development of biomechanical systems for heavy duty activities, including the lifting of heavy objects. The industry is eager in the adoption of this kind of systems since these decrease energy costs and avoid any type of air pollutant and heat that contribute to the global warming. The relationship between the biomechanics and material science is of great interest to determine the types of materials that can be used in the biomechanical systems fulfilling the standards required in the manufacturing processes of the industrial plants. The most used materials on these cases are chromium, nickel, niobium, titanium, tungsten, vanadium, and derivatives of iron (as alloy of steel with copper). The characteristics of mechanical strength, strain, stress, and corrosion effects of these materials are analyzed to determine if at some point they could cause a decrease in the functionality of the biomechanical system in the proposed working conditions. This is also a way to set the lifespan. These systems are more often used in the electronic and metalworking industry. There are several specialized computer programs for evaluation of biomechanical systems and devices functionality. The most commonly used programs are the Matlab, SolidWorks ${ }^{\circledR}$, and Catia ${ }^{\circledR}$. They are supported by functions to develop simulations with block diagrams and graphs. In these computer programs the biomechanical systems operation stages and its operability predictions are evaluated in real time. The evaluation of the corrosion effect on the biomechanical systems is very important because it can cause material fatigue that originates fractures or fissures that could generate mechanical and electrical failures that lead to potential accidents. There are various types of process control simulations appearing in computer programs to evaluate the functionality of a biomechanical system, as it is in the case of Matlab. One of these control processes is the PID controller, which consists of a proportional section $(P)$ without modification and two more sections defined as the integrative $(I)$ and the derivative $(D)$, which change according to the operation under analysis, in periods of time. Together the three sections generate similar required functions based on mathematical algorithms, represented in a block diagram with input and output simulations.
The steels are a large family of metals, with iron alloys in mixtures of carbon and other elements, being softened with different percentages of carbon at high levels (from $0.45 \%$ to $1.5 \%$ at most), medium levels (from $0.25 \%$ to $0.45 \%$ ), and low levels (under $0.25 \%$ ). The carbon steel is the most widely used, being an important alloy of iron and carbon that is commonly used in building constructions and other industrial applications due to their mechanical resistance and hardness. The typical carbon steel alloys may contribute up to $2.1 \%$ of its atomic weight. By varying the number of alloying elements or other process factors we get the consistency of the steel. Either varying the elements of the solute and the precipitation phase or by slowing the dislocation movements we can control the hardness and ductility of the produced metal (Tunil H. et al., 2002). In order to avoid the corrosion phenomena, protection films are used developed with the metals mentioned above. All these factors are considered in the design of the biomechanical systems, especially for those to be performing in the harsh environments of industrial activities. The properties of a steel are closely related to the percentages of the metals that compose it. For example, there is a large difference in the hardness between the carbon steel used in structures of buildings and the carbon steel utilized in an ornamental structure [1]. The rapid cooling of carbon steel with cold water when it is in red state generates more fragility, so it must be cooled slowly. Carbon steel heat treatment is another method that determines the physicochemical properties, which must match the standards required in industries [2]. Metallic materials are the most used for industrial plants, house structures, buildings, bridges, cars, and appliances. Artifacts exposed to aggressive environments in arid areas such as the city of Mexicali [3] suffer a high deterioration generated by the effect of corrosion mainly in carbon steel components. Another big factor in Mexicali is due to the presence of sulfurs emitted in the city mainly by the geothermal energy plant which supplies electricity to Mexicali, its valley, and some cities of Sonora and southwestern United States. It is located $20 \mathrm{~km}$ from the Mexicali city, emitting high levels of hydrogen sulfide $\left(\mathrm{H}_{2} \mathrm{~S}\right)$; this air pollutant reacts with the atmosphere and generates sulfur dioxide $\left(\mathrm{SO}_{2}\right)$. Other sulfurs emission sources are from the vehicular traffic and the oxidation ponds in this city of Mexicali. To ensure the quality and protection of the products made of carbon steel, this metallurgy plant "Industrial Metal, SA De CV" located in Mexicali city is using different types of metallic coatings [4]. Two different metal coatings are applied: one is a protection against corrosion and the other is the appropriate decorative polished layer [5].

\section{Methodology}

Currently, there are several models of biomechanical systems, they were developed using mathematical algorithms, and the functionality is evaluated by steps. In this case the first stage of this work is the design of the system and the second and final stage corresponds to the fabrication of the biomechanical system. Subsequently, an evaluation of materials for use in devices and biomechanical systems is 
performed, and parameters of hardness, mechanical strength, mechanical elasticity, and the effect of corrosion phenomena are analyzed. Furthermore, as a part of the evaluation we include the manufacturing costs of each metallic component, materials alloyed with steel. This research was suggested by the "Industrial Metal, SA De CV" as part of their industrial needs and requirements to increment the security standards. The analysis of the biomechanical system and the corresponding mathematical model and simulation was developed from 2014 to 2015. The next stage will be the manufacturing of this biomechanical system.

In this study the descriptive statistical technique called ANOVA is applied, with assessments and simulations in Matlab; also a statistical computer program is applied. Moreover, this same process is used to evaluate the materials and corrosions according to the ASTM standards as ASTM G1 (ASTM G1-03), G4 (ASTM G4-01), and G31 (ASTM G3172). And for the analysis of indoor corrosivity levels in this metallurgy company evaluation, we use the ISO standards as ISO 11844 (ISO11844, 2005), ISO 11844 (ISO11844, 2006), and the method AHRAE (AHRAE, 1999). The study is conducted in two stages as mentioned below.

(1) Evaluation of Biomechanical Models. Analyzing mathematical algorithms to obtain the most suitable ones for the fabrication of the biomechanical system, in accordance with the operations and standards required for heavy lifting in this "Industrial Metal, SA De CV" metallurgy company, located in Mexicali. This model could be also used in other companies or industries with similar needs.

(2) Analysis of Materials. Evaluation of some types of alloys with different metals to obtain the material required for the fabrication of the biomechanical system, for the particular operations required in this industry evaluated.

The analyses and assessments of the biomechanical systems operation help in the predictions related to their functionality. These analyses assist in the evaluation of the types of materials to be used in the biomechanical systems as well as in the mechanical, electrical, and electromechanical parameters required, along with the pollution and the climate variables that may affect its operation [6,7]. The steels are a large family of metals, with iron alloys in which it is mixed with carbon and other elements, being soft with different percentages of carbon at high level (0.45\% to $1.5 \%)$, medium $(0.25 \%$ to $0.45 \%)$, and low $(0.35 \%)$, but are never greater than $1.5 \%$. The carbon steel is the most widely used, being an important alloy of iron and carbon that is widely used in construction and other applications due to their mechanical resistance and hardness. The most common metal coatings are as follows.

(a) Copper Plating. The copper coating is the process in which a copper film is deposited on the metal material to be protected by using an electric current.

(b) Chrome Plating. This process is used with the technique of electroplating, where the thin protective film is deposited on the metal to be protected. The chrome film can be decorative and to increase the corrosion resistance, facilitate cleaning procedures, or increase the hardness of the surface.

(c) Nickel Plating. In this process the electroplating is used to deposit very thin films to have metallic surface protected. The nickel film may be for decorative aspects, corrosion resistance, or wear resistance, mainly [2].

\section{Results and Discussion}

The required models were developed and tested in a simulated environment as a way to evaluate its operation. This biomechanical model means to be part in a manufacturing process in the "Industrial Metal, SA De CV" company in an area requiring the lifting of heavy objects. The information obtained indicates that the carbon steel alloyed with chromium is the material that fits best in costs and functionality the requirements for the fabrication of this biomechanical system. Furthermore, the mathematical algorithms and graphs show the relation of the physical properties of the materials, which are correlated with climatic and air pollution parameters in the first graph and the bidirectional motor speed control used to lift the heavy objects. In addition, some analyses are conducted with the Matlab software, using mathematical algorithms to verify the optimal operation of the biomechanical system before the fabrication of it, saving this way time and money.

3.1. Design of the Biomechanical System. The design of the biomechanical system was carried out based on the requirements of the manufacturing processes area in the "Industrial Metal, SA De CV" company, where our study was developed for that purpose. Figure 1 shows a schematic diagram of the system used for the evaluations and simulations in the design of the final model fulfilling all the characteristics and standards demanded in the work environment of this metals industry.

3.2. Mathematical Modeling of Biomechanical Systems. We used the load supporting modeling process of Matlab software for the tensile stress analysis in our system. This is the force applied to the load to be lifted and the deformation occurs simultaneously at different points on the measured system. As shown in Figure 2, this modeling includes gain $(P)$, voltage $(I)$, and deformation $(D)$ as a part of the PID (Proportional-Integrative and Derivative) system.

Figure 2 shows a diagram of the PID controller; there we can observe the control processes of the main parameters involved, in the analysis of the functionality of the biomechanical system for industrial activities. These parameters are autoregulated by the feedback stage, and the system behavior is according to the mathematical algorithms it depends on, which is displayed in the graphs. This contributed in obtaining information on how the devices and the control mechanisms are activated by the movements of the biomechanical system. The signals representing these operations are shown in Figure 3. 


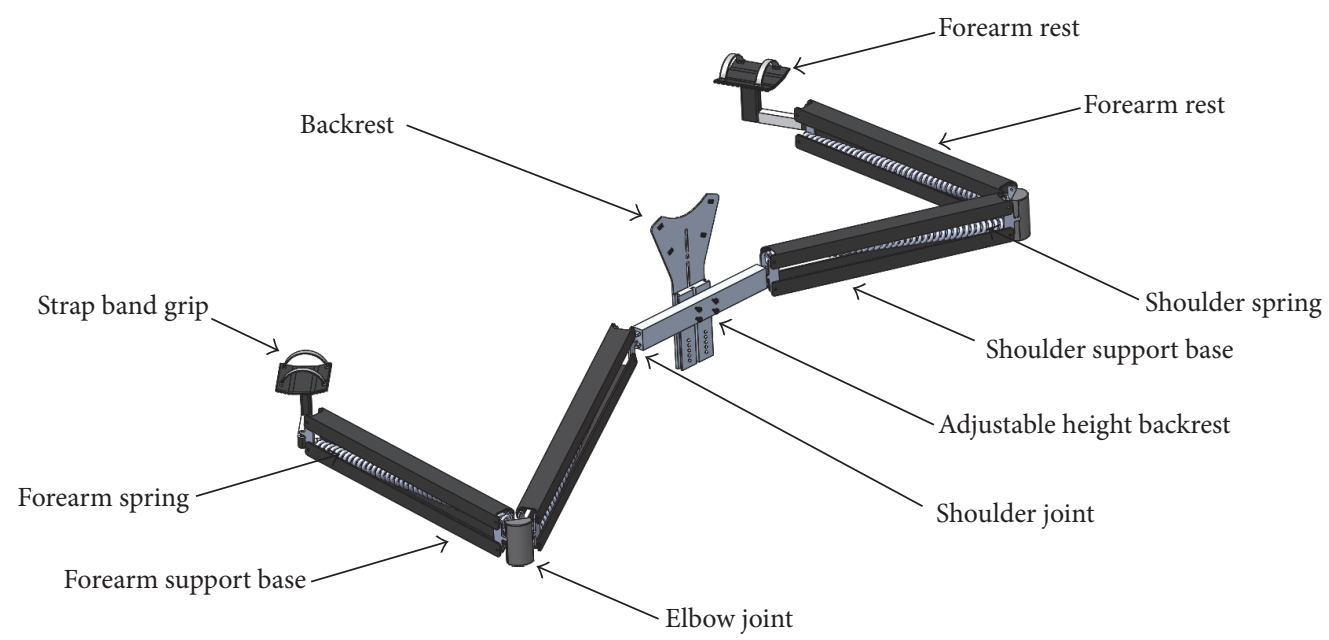

FIGURE 1: Schematic diagram of the system used in the evaluation and design of the final biomechanical model for the industrial activities.

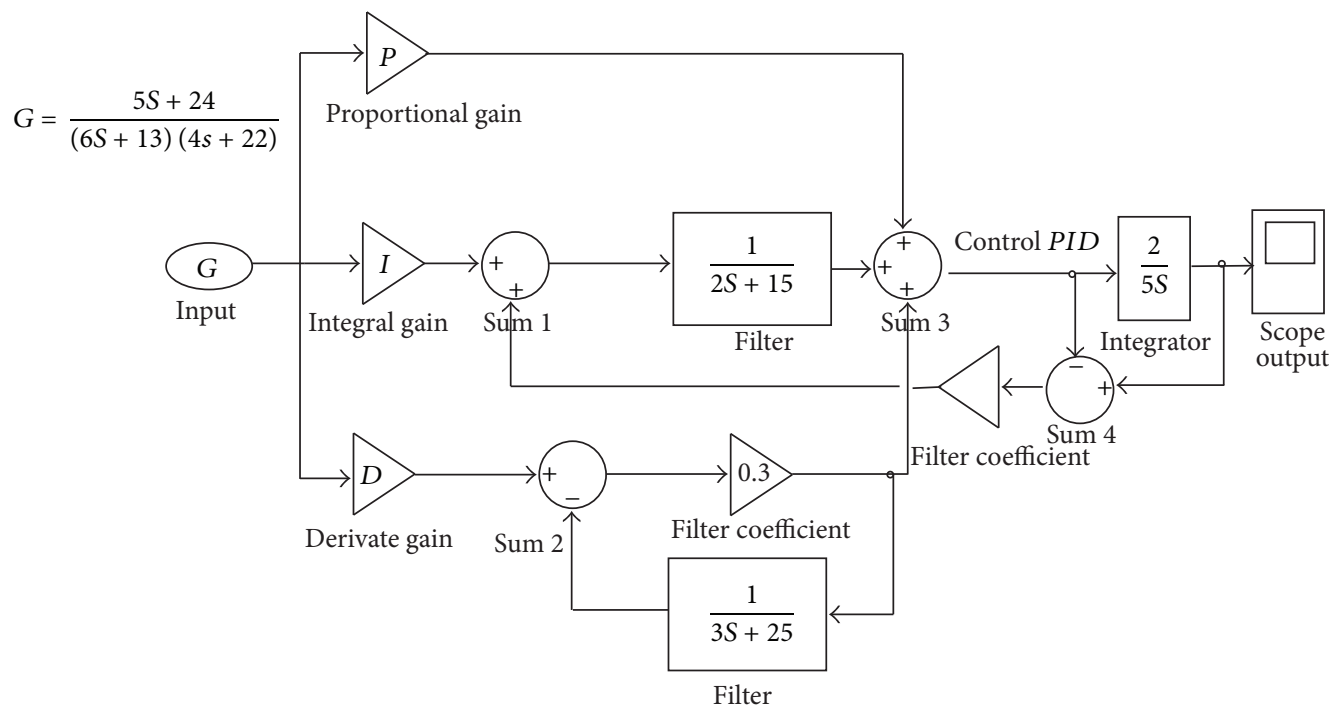

Figure 2: Diagram of the functionality of the proposed material for the manufacturing of the biomechanical system.

The $P$ stage, which represents the frequency of the input signal that is related to cycle time of the operation of the biomechanical system, is evaluated manually without the mathematical algorithms. The stage of integrative and derivative activity indicates how the actions can be autoregulated; the block of actions is controlled by an electromechanical device coupled to an electronic device, which are part of the mechanisms of the proposed biomechanical system. These mechanisms as a part of the simulation analysis are activated at the same frequency of the input signal. This generates an operation to determine the mechanical stress and deformation properties which are the most important ones based on the movements produced by the electromechanical and electronic devices. The results from the process described above can be seen in Figure 3, where the four essential activities of the PID controller are shown. The sinusoidal input signal is represented in Figure 3(a), which is the most commonly used in electromechanical and electronic systems that require high power levels for the operation, as it is the case of this heavy duty biomechanical system. These high power levels of energy are applied in industrial activities such as in the lifting of heavy objects, which is the case in the industrial plant evaluated, where we carried out this research analyzing the work cycles under different conditions.

Figure 3(b) illustrates the signal in a time period of 10 cycles; this input signal is required for the biomechanical system bidirectional motor to carry out the heavy lifting. This is done at minimum speed in a continuous movement to avoid any risk of injury for the workers performing these activities. Figure 3(c) is the result of the stress analysis in the same period of time. It represents the integrative section that indicates the voltage levels correlation from the proposed material (carbon steel with an alloy of chromium). The functionality of the mechanisms mentioned above for the heavy lifting operation is evaluated based on these results. The feed for the analysis of the initial operation of this 


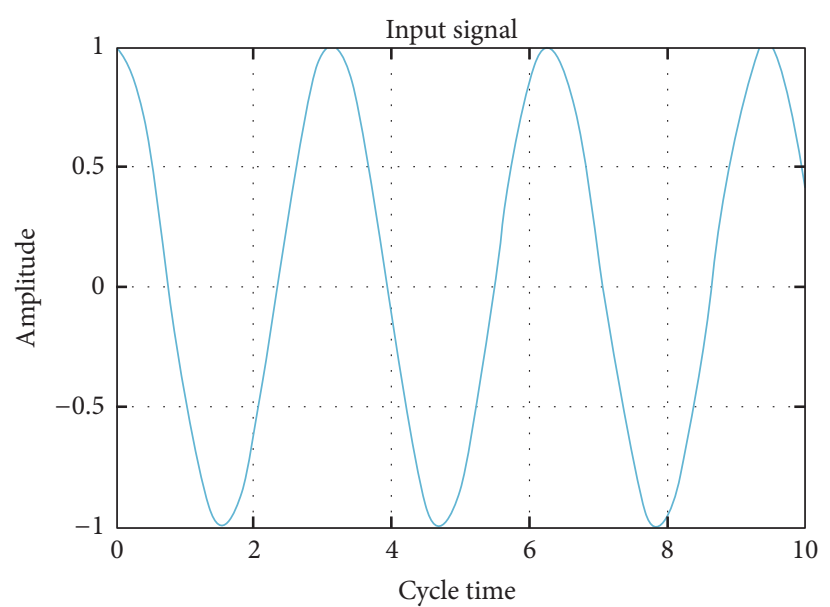

(a)

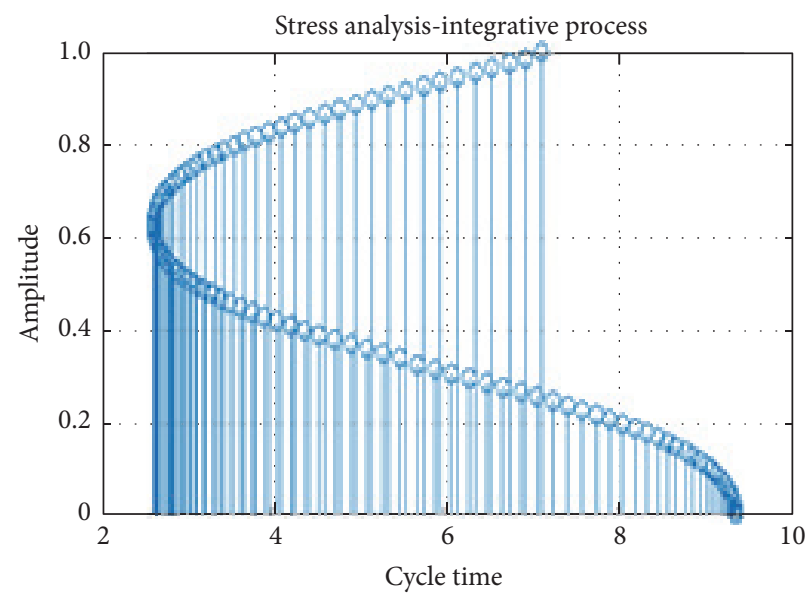

(c)

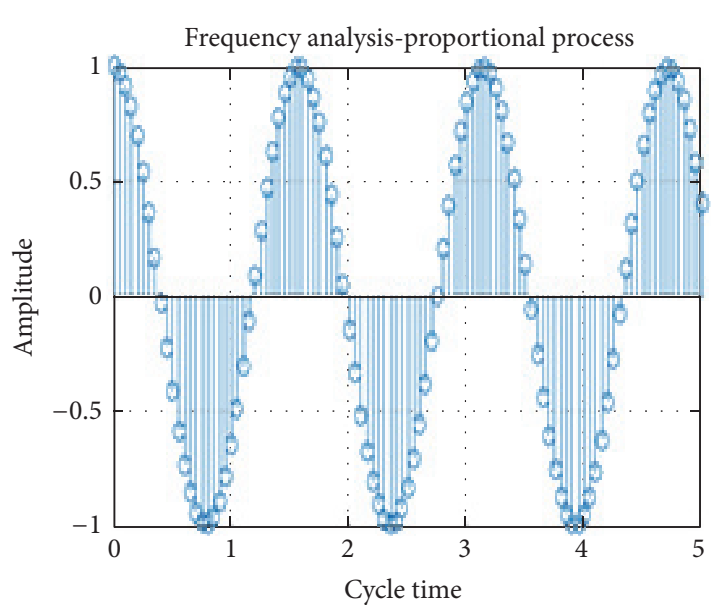

(b)

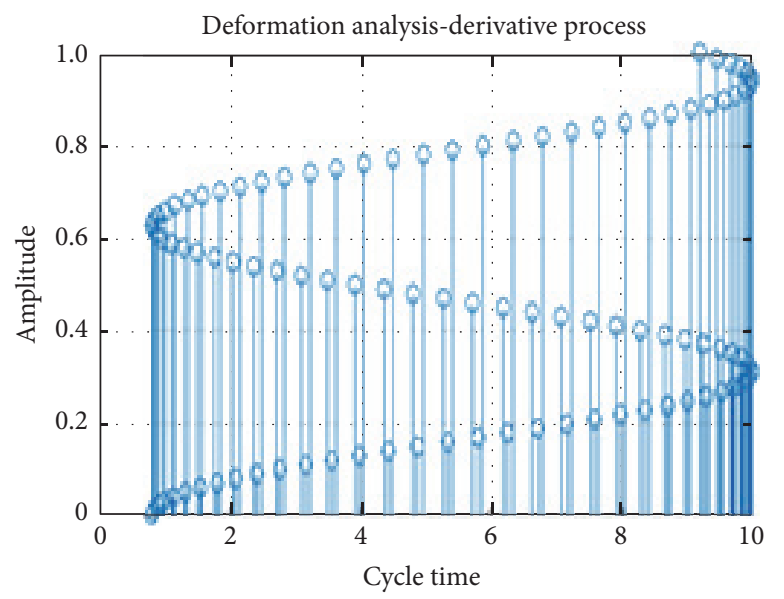

(d)

FIGURE 3: Simulation of operation of the SS 304 material for the biomechanical system.

function starts with a delay of two seconds from the process activity in the PID controller. Figure 3(c) illustrates the stress analysis in the proposed material. The evaluation process starts at the end of the tenth cycle, and the obtained values are returned after about two seconds of operation of the biomechanical system. That is, after almost ten seconds in total of operation of the biomechanical system, it begins to exert the first tension force; the appropriate levels of tension for the optimal functionality of this system are determined through the feedback of the mechanisms involved.

As the feedback function is processed, it is observed that the cycle restarts about every two seconds. This is because the coupling of the electrical signals in the PID feeds the electromechanical and electronic devices, and a time delay is required to begin the operations. The simulation analysis shows that the process under evaluation is optimal and that this design can be implemented in the manufacturing of the biomechanical system.

The material stress is evaluated every two seconds looking for the possibility of a fracture and a consequent failure in the mechanisms constructed with this metal. The increased tension in each analysis period in the integrative process was exactly after 9.5 seconds from the beginning of each stage in the controlled evaluation environment.

Figure 3(d) indicates a similar evaluation at the same cycles of time compared to that in the other figures, which shows that from one second exactly the evaluation starts and finishes in the tenth cycle. After that the process starts all over again, providing again the feedback after one second and finishing after another ten cycles, completing another full period for the biomechanical system. Figure 3(d) represents the deformation of the material under evaluation; the outcome means that this material fulfills perfectly the requirements of the biomechanical system. Another mechanical property of serious importance is the corrosion resistance, since it causes material deterioration and damage by fatigue. This can lead to a faster breakage than expected with even chances of a fatal accident. The mechanical property is assessed in Table 1. The importance of this kind of analysis is clear, to avoid any event that would put at risk the life or health of any of the workers in the company. As is indicated in Figure 3, the material chosen for this is the Stainless Steel 304 (or SS 304).

Table 1 shows the values of the evaluated parameters, which indicate the greater number of cycles per unit of 
TABLE 1: Mechanical properties and function analysis of the electromechanical and electronic mechanisms.

\begin{tabular}{lcccc}
\hline Time, cycles by minute & $\begin{array}{c}\text { Correlation rate } \\
\mathrm{mg} \cdot \mathrm{m}^{2} / \text { year }\end{array}$ & $\begin{array}{c}\text { Stress } \\
\mathrm{KPa}\end{array}$ & $\begin{array}{c}\text { Deformation } \\
\%\end{array}$ & Observations \\
\hline 2 & 12 & 10 & 0.3 & $\begin{array}{c}\text { Materials do not present negative effect } \\
\text { Materials do not present negative effect } \\
4\end{array}$ \\
23 & 15 & 0.5 & $\begin{array}{c}\text { Materials present small stains and can be } \\
\text { a negative effect }\end{array}$ \\
6 & 38 & 20 & 1.0 & $\begin{array}{c}\text { Materials present small stains and can be } \\
\text { a negative effect }\end{array}$ \\
10 & 45 & 30 & 1.4 & $\begin{array}{c}\text { Materials present big stains and can be a } \\
\text { negative effect as fracture }\end{array}$ \\
\hline
\end{tabular}

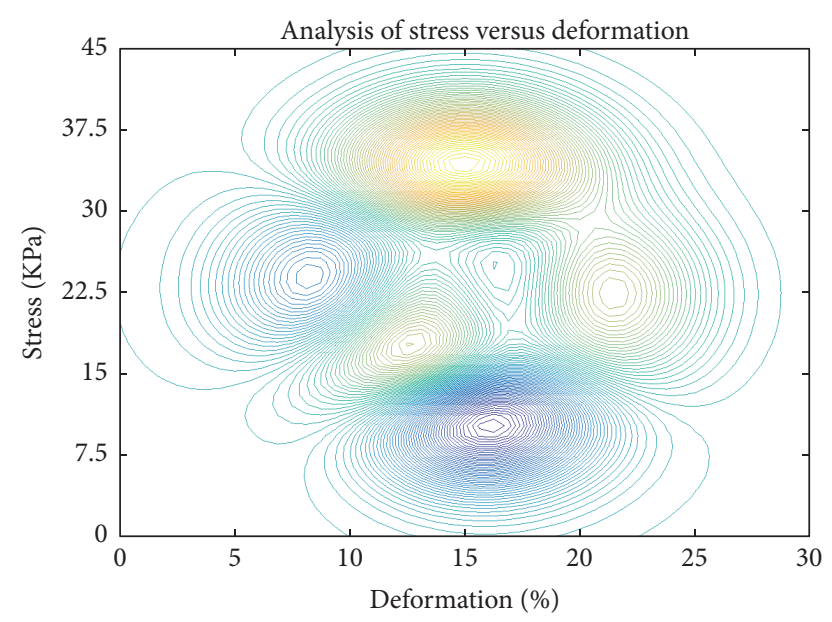

FIGURE 4: SS 304 stress and deformation correlation analysis in the ten cycles per minute period.

time and the presence of corrosion, together with high strain indices, can degenerate the properties of the carbon steel without the alloy, causing a fast deformation and the possibility of a fracture. Figure 4 shows a correlation at different levels of stress and strain processes of the simulation performed with the mathematical algorithms. As expected, the mechanical properties have influence in the operation of the entire biomechanical system. As shown in Figure 4, the deformation process starts at about $10 \mathrm{KPa}$ and the different levels of stress are represented with different indices of colors, where the blue and green together show the first point of deformation, and stress levels near $35 \mathrm{KPa}$ are in yellow tone. This is a big negative impact on the functionality of the proposed material, where deformation can be up to $10 \%$ or even slightly higher. This could generate a lack of confidence in the use of the biomechanical system when performing the activities of heavy lifting in the company evaluated. As a solution, we recommend the use of carbon steel with alloy of chrome to avoid the presence of the corrosion phenomena.

Furthermore, an analysis of the speed control for the bidirectional motor was carried out to avoid quick and drastic movements that can cause a damage in the arms, spine, or legs of the workers in charge of the operation of this biomechanical system. This is represented in Figure 5 as a block diagram with two input signals (square and

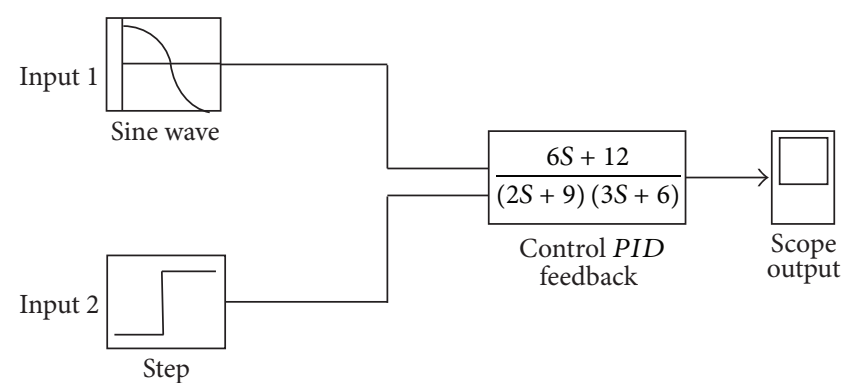

Figure 5: Diagram of the speed control for the motor in the biomechanical system.

sinusoidal waves) and the feedback for the speed control of the bidirectional motor. The coupling of the two signals is necessary to have a constant and immediate acceleration through the electronic control devices that can maintain a fixed speed as required. The input and output signals are shown in Figure 6.

In Figure 6 the two waves (square and sinusoidal) are shown used as input signals and the resulting output signal for the controlled speed. This is based on the mathematical algorithm that supports the optimal performance of the full biomechanical system.

The two input signals are represented in Figures 6(a) and 6(b), with 100 cycles per time unit; these signals are fed to the mathematical algorithm giving a single output signal illustrated in Figure 6(c), where control is 80 cycles per time unit, showing a slight delay in response due to the operations of the electronic devices (transistors and relays, coupled to integrated circuits). The control signal is represented in Figure 6(c), where the start of the operation of the motor is observed, with the negative cycle indicating the movement in one direction, reaching the level of 0 and is increased to the positive level that represents the movement in the other direction.

3.3. The Use of Carbon Steel Coating. The materials evaluated to be applied as coatings on the carbon steels metal were analyzed according to the costs and functionality, at a theoretical level by the Density Functional Theory (DFT) program used for molecular modeling, obtaining the results through the processes analysis, as shown in Table 2. The testing of different 


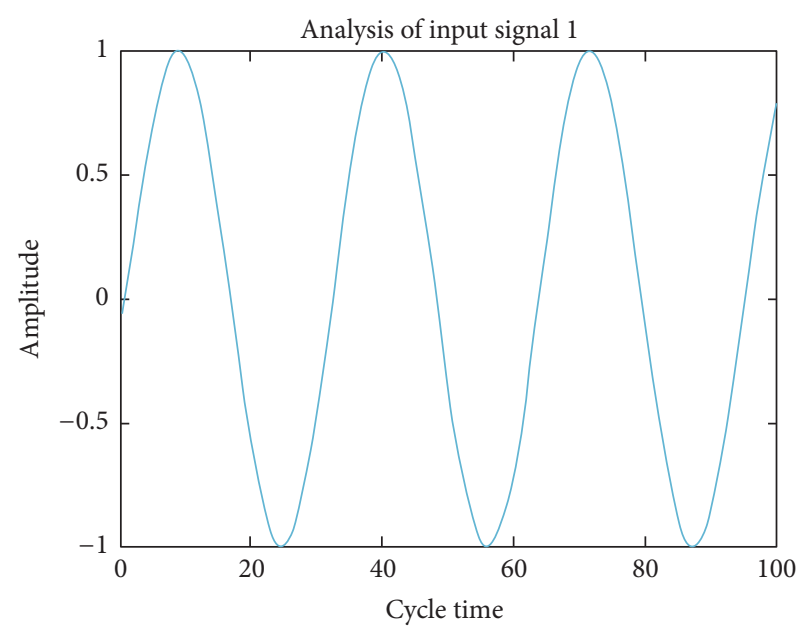

(a)

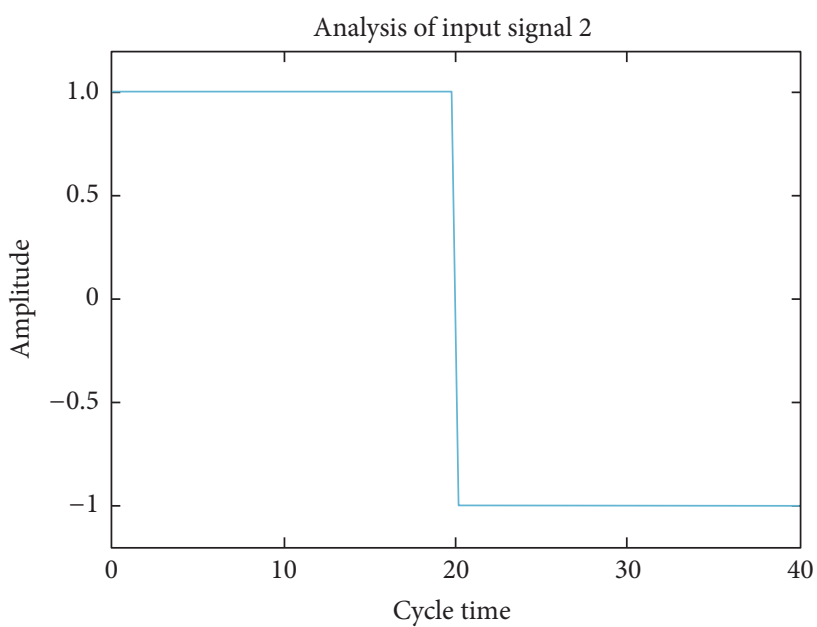

(b)

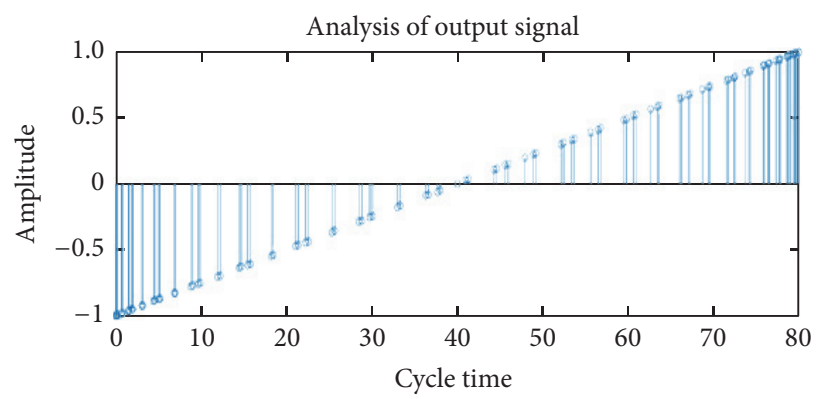

(c)

FIGURE 6: Simulation of the motor speed control for the biomechanical system made of SS 304 .

TABLE 2: Characterization of phases of alloys for coatings in carbon steels.

\begin{tabular}{|c|c|c|c|}
\hline Alloy & Percentage of affinity (\%) & Change of phase & Crystal parameters \\
\hline $\mathrm{Fe}-\mathrm{C}-\mathrm{Cu}-\mathrm{Cr}$ & $80 \%$ & FT & $a=5.455, c=5.145$ \\
\hline $\mathrm{Fe}-\mathrm{C}-\mathrm{Cu}-\mathrm{Ni}$ & $75 \%$ & FT & $a=5.615, c=5.325$ \\
\hline $\mathrm{Fe}-\mathrm{C}-\mathrm{Cr}$ & $80 \%$ & FM & $a=5.785, b=5.150, c=5.360$ \\
\hline $\mathrm{Fe}-\mathrm{C}-\mathrm{Cu}-\mathrm{Cr}-\mathrm{Ni}$ & $85 \%$ & FM & $a=5.660, b=5.235, c=5.345$ \\
\hline
\end{tabular}

Monoclinic phase change (FM) to tetragonal $(\mathrm{FT})=$ FMFT; tetragonal phase change $(\mathrm{FT})$ to monoclinic $(\mathrm{FM})=\mathrm{FTFM}$.

alloys of metals is with the goal of obtaining the required functionality within the standards and at the lower cost.

Table 3 shows the configuration of the observed phases in the process of forming the alloys; the three with the higher affinity are the ones that we propose for the coatings, since those have more binding or adherence properties. The monoclinic and tetragonal phases are the most common in the manufacturing processes of carbon steels with body centered crystalline structures. The best material out of this study is the alloy of carbon steel with chrome.

3.4. Costs of Coatings. The costs of the metals (copper, chromium, and nickel) used in the coating processes of the steel manufactured by the company evaluated fluctuated in the period of one year (2014), as indicated in Table 3 based on public international data from a global metal analysis company.
TABLE 3: Analysis of copper, chromium, and nickel prices in US dollars (2014).

\begin{tabular}{lccc}
\hline \multirow{2}{*}{ Months } & \multicolumn{3}{c}{ Cost of metals, dollars/pounds } \\
& Copper & Chrome & Nickel \\
\hline January & 3.12 & 1.02 & 7.84 \\
February & 3.15 & 1.04 & 8.12 \\
March & 3.18 & 1.05 & 8.25 \\
April & 3.23 & 1.08 & 8.36 \\
May & 3.26 & 1.06 & 8.30 \\
June & 3.32 & 1.03 & 8.35 \\
July & 3.36 & 1.07 & 8.87 \\
August & 3.26 & 0.98 & 6.67 \\
September & 3.22 & 1.03 & 6.89 \\
October & 3.17 & 1.05 & 7.43 \\
November & 3.25 & 1.06 & 7.65 \\
December & 3.36 & 1.08 & 7.79 \\
\hline
\end{tabular}

Source: Kitco Gold index, http://www.kitco.com. 
TABLE 4: Correlation of costs, manufacturing process, and time of deposition (coating).

\begin{tabular}{|c|c|c|c|c|c|c|c|c|c|c|}
\hline \multirow{3}{*}{\multicolumn{2}{|c|}{ Specifications of coatings }} & \multicolumn{9}{|c|}{ Metals } \\
\hline & & \multicolumn{3}{|c|}{ Copper } & \multicolumn{3}{|c|}{ Chrome } & \multicolumn{3}{|c|}{ Nickel } \\
\hline & & \multirow[t]{2}{*}{ M.gr. } & \multirow[t]{2}{*}{$t$} & \multirow[t]{2}{*}{ C } & \multirow[t]{2}{*}{ M.gr. } & \multirow[t]{2}{*}{$t$} & \multirow[t]{2}{*}{$C$} & \multirow[t]{2}{*}{ M.gr. } & \multirow[t]{2}{*}{$t$} & \multirow[t]{2}{*}{$C$} \\
\hline$D, \mathrm{~cm}$ & $e, \mathrm{~mm}$ & & & & & & & & & \\
\hline 2.00 & 0.0025 & 0.14 & 1426 & 0.95 & 0.11 & 4191 & 1.17 & 0.14 & 1532 & 1.43 \\
\hline 2.50 & 0.0030 & 0.21 & 2139 & 1.22 & 0.17 & 6288 & 1.30 & 0.21 & 2298 & 1.67 \\
\hline 3.00 & 0.0035 & 0.30 & 2994 & 1.45 & 0.24 & 8803 & 1.44 & 0.29 & 3218 & 1.88 \\
\hline 3.50 & 0.0040 & 0.39 & 3993 & 1.63 & 0.32 & 11737 & 1.59 & 0.39 & 4290 & 2.11 \\
\hline 4.00 & 0.0045 & 0.50 & 5133 & 1.79 & 0.41 & 15091 & 1.72 & 0.50 & 5515 & 2.34 \\
\hline 4.50 & 0.0050 & 0.63 & 6417 & 1.88 & 0.51 & 18863 & 1.88 & 0.63 & 6895 & 2.78 \\
\hline 5.00 & 0.0055 & 0.77 & 7843 & 2.07 & 0.62 & 23055 & 1.99 & 0.77 & 8427 & 3.13 \\
\hline 5.50 & 0.0060 & 0.93 & 9411 & 2.13 & 0.75 & 27666 & 2.23 & 0.92 & 10112 & 3.67 \\
\hline 6.00 & 0.0065 & 1.10 & 11122 & 2.22 & 0.88 & 32696 & 2.85 & 1.09 & 11951 & 4.23 \\
\hline 6.50 & 0.0070 & 1.30 & 12976 & 2.33 & 1.03 & 38146 & 3.67 & 1.27 & 13943 & 4.89 \\
\hline
\end{tabular}

$[D, \mathrm{~cm}]$ diameter in centimeters of the steel to be covered; $[e, \mathrm{~mm}]$ coating thickness in millimeters; [M.gr.] grams of metal used for the coating; $[t]$ time in seconds for the deposition; $[C]$ cost in pesos for coating process per meter.

As we can see the costs of the metals did not change much. In Table 3 the costs of obtaining the raw material for the manufacturing stages of the coatings are added, plus the costs of the manufacturing processes with the steel protection methods. Moreover, in this evaluation the amounts of each metal are considered in grams for the coating of the steel, in addition to the process cycles required in applying each material deposition.

Table 4 shows the effect of the coating process after each round, obtaining the respective geometric figure, according to their physical and chemical characteristics correlated with the costs of the deposition process. As the diameter of the area to be covered and the coating thickness increase, the amount in grams of the metal to be used for the covering, the deposition time, and the costs of the coating process for each metal increase as well.

\section{Conclusions}

The aim of this research is to solve the problem of human injuries mainly in the spine caused by the lifting of heavy objects as a part of the operations required in one particular station at the host industry supporting this study. Our analysis concluded that by its cost and mechanical properties the carbon steel alloyed with chrome is the adequate material to use in this particular case. Other results worth pointing out are the motor function regulation for its use in the biomechanical system and the development of the mathematical functions for the analysis of the stress and deformation correlation.

Furthermore, a corrosion resistance evaluation is performed according to the input signals from the mechanical, electromechanical, and electronic devices required in the operations; this is to assure for a long time the quality of the functionality of all the biomechanical system proposed to the company for the lifting of objects up to one hundred kilograms.
The support from the company is mainly to replace some obsolete machinery and equipment and reduce the power consumption and the use of fuels that generate high levels of pollution and heat, which is a big problem in the city of Mexicali in particular and in the world in general due to the climate change and greenhouse effect. The relevance of this research is the design and analysis of biomechanical systems that can be used directly in the industry production lines to make all the process more efficient and less prone to accidents which in both ways save a lot of money by increasing also the productivity and performance of the workers. Analyzing the Matlab simulation tool and its mathematical functions, we found that there is a high level of confidence and acceptance in that software that has been used in similar researches as a validation tool. In the information provided as a part of this document the coupling of the mechanical, electromechanical, and electronic systems to integrate the biomechanical system is observed.

\section{Competing Interests}

The authors declare that there is no conflict of interests regarding the publication of this paper.

\section{Acknowledgments}

The authors thank the "Industrial Metal, SA De CV" that opened its doors to all the participating institutions as well as the full support provided that made this research possible.

\section{References}

[1] M. Fernández, Preparación Mecánica y Química de Minerales, Editorial Dossat SA, 2006.

[2] A. Reardon, "Metallurgy for the non-metallurgist," in ASTM Standards Book, ASM International, 2nd edition, 2011. 
[3] L.-B. Gustavo, V.-S. Benjamín, and S.-W. Michael, "Atmospheric corrosion in the sea food industry in the Northwwest of México," Revista Científica Instituto Politécnico, vol. 16, no. 2, pp. 67-73, 2012.

[4] G. L. Badilla, B. V. Salas, and M. S. Wiener, "Micro and nano corrosion in steel cans used in the seafood industry," in Scientific, Health and Social Aspects of the Food Industry, InTech, 2012.

[5] M. Anthony, D. Jones, and H. Rayner, "An introduction to microstructures, processing and design of steels," Materials, Methods and Treatments Journal, vol. 3, no. 2, pp. 56-63, 2002.

[6] A. Tsouknidas, S. Savvakis, Y. Asaniotis, K. Anagnostidis, A. Lontos, and N. Michailidis, "The effect of kyphoplasty parameters on the dynamic load transfer within the lumbar spine considering the response of a bio-realistic spine segment," Clinical Biomechanics, vol. 28, no. 9-10, pp. 949-955, 2013.

[7] J. S. Temenoff and A. G. Mikos, Biomaterials: The Intersection of Biology and Materials Science, Pearson/Prentice Hall, Upper Saddle River, NJ, USA, 2008.

[8] ASTM Standards, Standards to Technical Experiments, ASTM, 2000. 

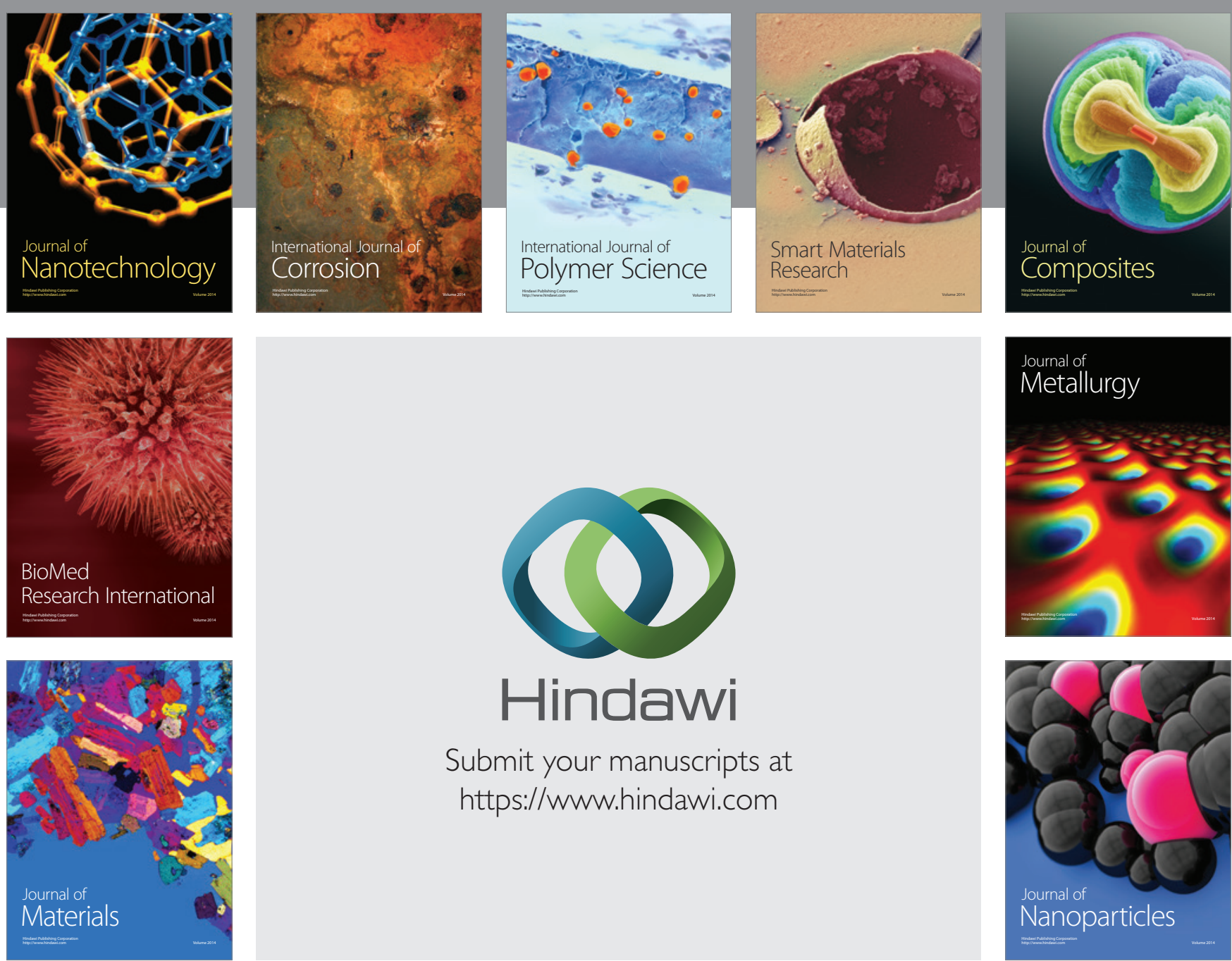

\section{Hindawi}

Submit your manuscripts at

https://www.hindawi.com

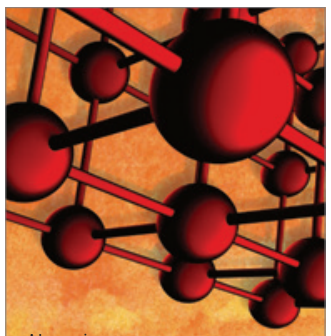

Materials Science and Engineering
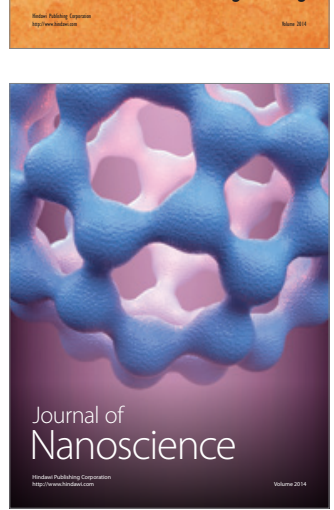
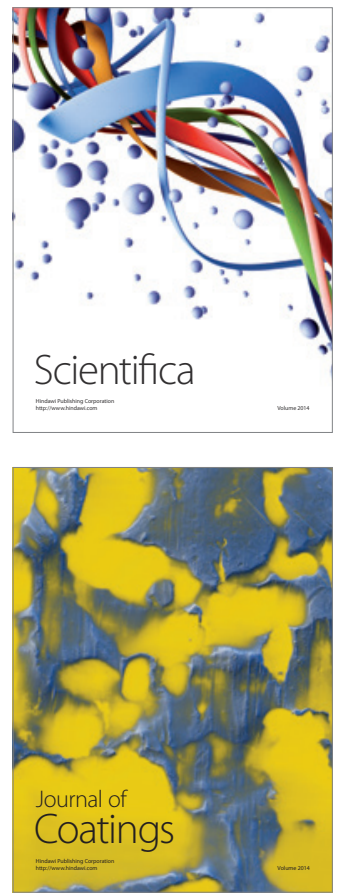
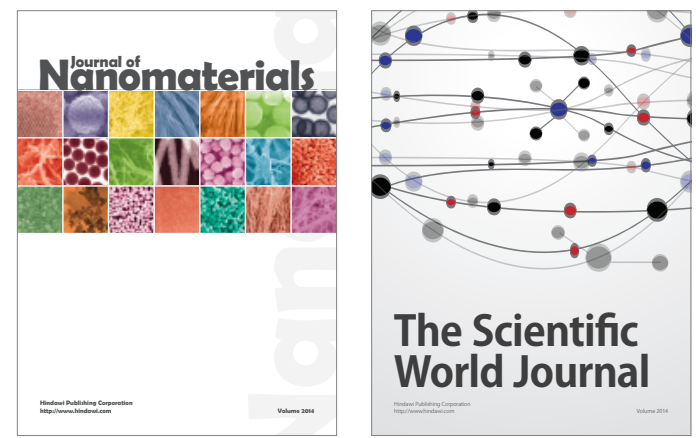

The Scientific World Journal
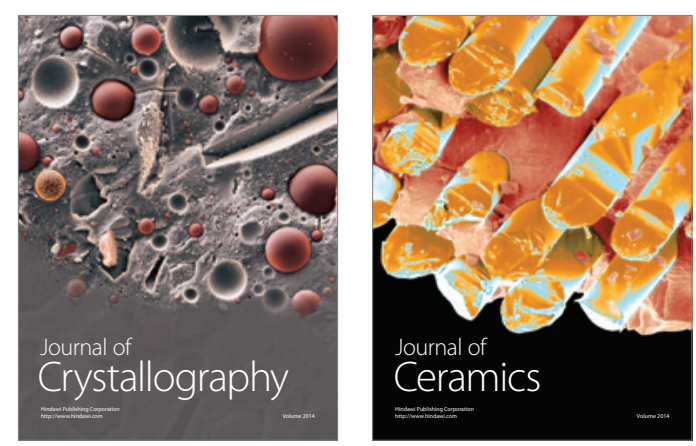
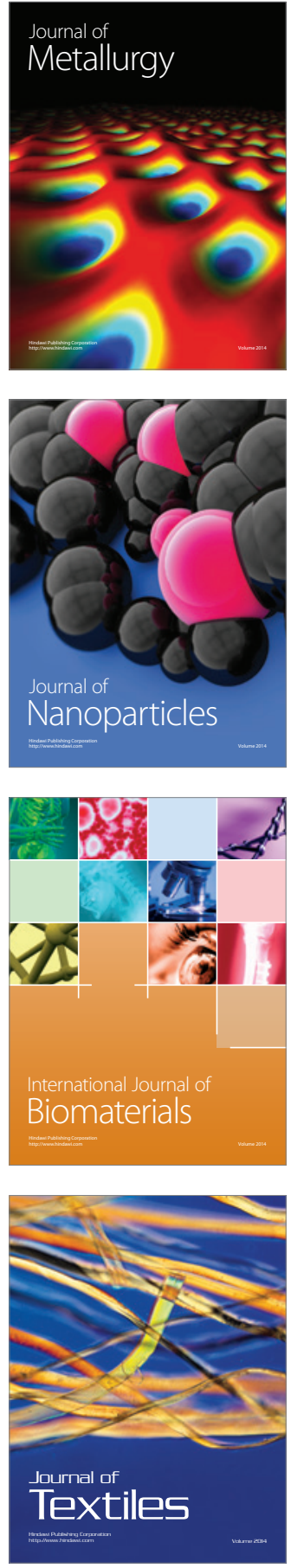